\title{
Dihydroartemisinin-Loaded Magnetic Nanoparticles for Enhanced Chemodynamic Therapy
}

OPEN ACCESS

Edited by:

Wei TaO,

Harvard Medical School,

United States

Reviewed by:

Zhongliang Wang,

Xidian University, China

Peihong Ni,

Soochow University, China

${ }^{*}$ Correspondence:

Haibao Peng

haibaopeng@gmail.com

Jing Tang

jingtang@stanford.edu

Wuli Yang

wlyang@fudan.edu.cn

Specialty section:

This article was submitted to

Experimental Pharmacology

and Drug Discovery,

a section of the journal

Frontiers in Pharmacology

Received: 18 December 2019

Accepted: 19 February 2020

Published: 10 March 2020

Citation:

Guo S, Yao X, Jiang Q, Wang $K$,

Zhang $Y$, Peng $H$, Tang $J$ and Yang $W$

(2020) Dihydroartemisinin-Loaded Magnetic Nanoparticles for Enhanced

Chemodynamic Therapy.

Front. Pharmacol. 11:226.

doi: 10.3389/fphar.2020.00226

\author{
Shengdi Guo', Xianxian Yao', Qin Jiang', Kuang Wang', Yuanying Zhang', \\ Haibao Peng ${ }^{2 *}$, Jing Tang ${ }^{3 *}$ and Wuli Yang ${ }^{1 *}$
}

${ }^{1}$ State Key Laboratory of Molecular Engineering of Polymers, Department of Macromolecular Science, Fudan University, Shanghai, China, ${ }^{2}$ Department of Pharmaceutical Sciences, Shanghai University of Traditional Chinese Medicine, Shanghai, China, ${ }^{3}$ Department of Materials Science and Engineering, Stanford University, Stanford, CA, United States

Recently, chemodynamic therapy (CDT) has represented a new approach for cancer treatment with low toxicity and side effects. Nonetheless, it has been a challenge to improve the therapeutic effect through increasing the amount of reactive oxygen species (ROS). Herein, we increased the amount of ROS agents in the Fenton-like reaction by loading dihydroartemisinin (DHA) which was an artemisinin (ART) derivative containing peroxide groups, into magnetic nanoparticles (MNP), thereby improving the therapeutic effect of CDT. Blank MNP were almost non-cytotoxic, whereas three MNP loading ART-based drugs, MNP-ART, MNP-DHA, and MNP-artesunate (MNP-AS), all showed significant killing effect on breast cancer cells (MCF-7 cells), in which MNP-DHA were the most potent. What's more, the MNP-DHA showed high toxicity to drug-resistant breast cancer cells (MCF-7/ADR cells), demonstrating its ability to overcome multidrug resistance (MDR). The study revealed that MNP could produce ferrous ions under the acidic condition of tumor microenvironment, which catalyzed DHA to produce large amounts of ROS, leading to cell death. Further experiments also showed that the MNP-DHA had significant inhibitory effect on another two aggressive breast cancer cell lines (MDA-MB-231 and MDA-MB-453 cells), which indicated that the great potential of MNP-DHA for the treatment of intractable breast cancers.

Keywords: chemodynamic therapy, reactive oxygen species, multidrug resistance, dihydroartemisinin, magnetic nanoparticle, breast cancer

\section{INTRODUCTION}

Chemodynamic therapy (CDT) is a tumor therapeutic strategy which generates abundant reactive oxygen species (ROS) in tumor sites via the Fenton reaction or Fenton-like reaction (Tang et al., 2019; Yan et al., 2019). Generally, specific nanomaterials produce ions as catalysts, which cleave the endoperoxide linkages in ROS agents to produce ROS (Bokare and Choi, 2014). In the classical Fenton reaction, the catalyst is ferrous ions produced under the acidic condition of tumor microenvironment and the ROS agent is the excessive hydrogen peroxide $\left(\mathrm{H}_{2} \mathrm{O}_{2}\right)$ in cancer cells (Li et al., 2015; Chen et al., 2017). The overproduction of ROS is cytotoxic, which could damage membrane and oxidize lipids in cells, further leading to antitumor performance via apoptosis and/or ferroptosis (Reed and Pellecchia, 2012; Yue et al., 2018; Wan et al., 2019; Xu X. et al., 2019). 
Owing to the fact that CDT needs to be activated by the stimulation of the tumor's endogenous microenvironment, for example, low $\mathrm{pH}$ and elevated $\mathrm{H}_{2} \mathrm{O}_{2}$ concentration, the overproduction of ROS is almost exclusively achieved at the tumor site and consequently CDT has very low toxicity and side effects on normal tissues (Breunig et al., 2008; Chen et al., 2017, 2019). Compared with other treatment strategies displaying non-negligible dark toxicity, like chemotherapy, radiotherapy, photodynamic therapy, and sonodynamic therapy, CDT has the advantage that it is highly selective and specific (Osaki et al., 2011; Tang et al., 2013, 2018; Song et al., 2016; Cho et al., 2017; Men et al., 2018; An et al., 2019; Yang et al., 2019). However, the generation of ROS will be limited to the conditions of the tumor site, so the ideas of inducing preferential cancer cell death through exogenous ROS generating agents have gained considerable momentum.

Since the efficiency of ROS production by Fenton or Fentonlike reaction is dependent on catalysts and ROS agents, a series of studies have enhanced intracellular ROS production mainly in two aspects. On one hand, varieties of materials increasing the amount of ROS are developed from the perspective of catalysts (Zheng et al., 2017; Ma et al., 2019). Increasing the number of catalyst ions is a straightforward method to promote the efficiency of CDT. Shi group reported the facile synthesis of amorphous iron nanoparticles, which could be rapidly ionized to release $\mathrm{Fe}^{2+}$ ions in an acidic tumor microenvironment for CDT (Zhang C. et al., 2016). Besides iron ions, many other metal ions, including $\mathrm{Mn}^{2+}, \mathrm{Cu}^{2+}$, and $\mathrm{Co}^{2+}$ ions, could also show Fenton-like activities (Ember et al., 2009; Xu et al., 2011; Bokare and Choi, 2014; Poyton et al., 2016). Due to the GSH depletion property of $\mathrm{MnO}_{2}$, Chen group used $\mathrm{MnO}_{2}$-coated mesoporous silica nanoparticles to destroy tumor cells, resulting in GSH depletion-enhanced CDT (Lin et al., 2018). On the other hand, despite the concentration of $\mathrm{H}_{2} \mathrm{O}_{2}$ in tumor cells is higher than normal tissues, the amount of $\mathrm{H}_{2} \mathrm{O}_{2}$ is still too low to achieve good therapeutic effect (Szatrowski and Nathan, 1991). Therefore, from the perspective of ROS agents, it is viable to raise the efficiency of ROS production via increasing the amount of ROS agents in cancer cells (Huo et al., 2017). Ge group constructed integrated multifunctional polymeric nanoparticles in which ascorbyl palmitate molecules can selectively generate $\mathrm{H}_{2} \mathrm{O}_{2}$ in tumor tissues, sequentially improving the therapeutic effect of CDT (Wang et al., 2018).

In addition, it is also a feasible way to load drugs whose treatment principles are based on Fenton or Fenton-like reactions into materials to increase the quantity of ROS agents. Many reports have shown that artemisinin (ART) and its derivatives, as frontline drugs against malarial infections, achieve antimalarial effects by Fenton-like reaction, the specific process of which is that under the catalysis of ferrous heme the weak endoperoxide linkages ( $\left.\mathrm{R}-\mathrm{O}-\mathrm{O}-\mathrm{R}^{\prime}\right)$ in drugs break resulting in the formation of toxic ROS (Olliaro et al., 2001; Krishna et al., 2004; Golenser et al., 2006; Tu, 2011). Currently, ART and its derivatives have also been used as tumor therapeutic agents for cancers via CDT (Wang et al., 2016; Wang L.L. et al., 2019; Yao et al., 2018; Sun et al., 2019). What's more, it has been found that ART and its derivatives showed sensitivity against multidrug resistance (MDR) cancer cells, as that some common ART-based drugs were not transported by P-glycoprotein (P-gp), which mediates cellular MDR by actively pumping antitumor drugs outside the cancer cells (Kruh and Belinsky, 2003; Szakacs et al., 2006; Prasad et al., 2012; Zhong et al., 2016; Wang Y. et al., 2019). Therefore, ART and its derivatives exhibit the potential to overcome tumor MDR.

In this work, as shown in Scheme 1, ART and its two derivatives, dihydroartemisinin (DHA) and artesunate (AS), were loaded into magnetite nanoparticles (MNP) respectively, used for CDT enhancement. After loading these drugs, the non-cytotoxic MNP showed high toxicity to breast cancer cells. Subsequently, dihydroartemisinin-loaded magnetic nanoparticles (MNP-DHA) with the best inhibitory effect exhibited the ability to effectively kill MCF-7/ADR cancer cells, and the mechanism of MNPDHA achieving therapeutic effect was investigated. Further experiments indicated that MNP-DHA possessed excellent

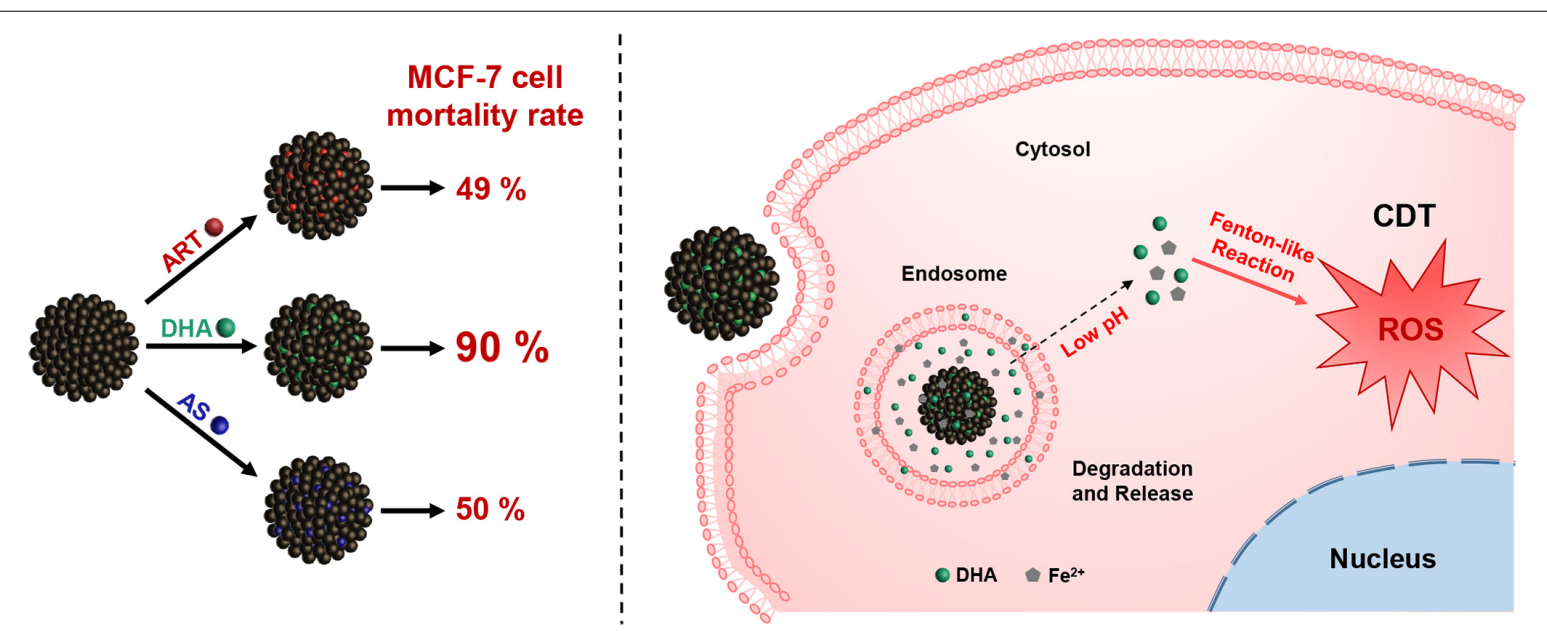

SCHEME 1 | Schematic illustration of dihydroartemisinin-loaded magnetic nanoparticles for enhanced chemodynamic therapy. 
inhibition ability for other intractable breast cancer cells and had a good application prospect.

\section{MATERIALS AND METHODS}

\section{Materials}

Iron (III) chloride hexahydrate $\left(\mathrm{FeCl}_{3} \cdot 6 \mathrm{H}_{2} \mathrm{O}\right)$, sodium acetate anhydrous $(\mathrm{NaOAc})$, trisodium citrate dihydrate $\left(\mathrm{Na}_{3} \mathrm{Cit} \cdot 2 \mathrm{H}_{2} \mathrm{O}\right)$, ethanol, sodium hydroxide $(\mathrm{NaOH})$, and dimethyl sulfoxide (DMSO) were purchased from Shanghai Chemical Reagents Company. Doxorubicin hydrochloride (DOX), artemisinin (ART), dihydroartemisinin (DHA), artesunate (AS), 1,3-diphenylisobenzofuran (DPBF), sodium dihydngen phosphate anhydrous $\left(\mathrm{NaH}_{2} \mathrm{PO}_{4}\right)$ and sodium phosphate dibasic anhydrous $\left(\mathrm{Na}_{2} \mathrm{HPO}_{4}\right)$ were purchased from Shanghai Aladdin Chemistry Company. $2^{\prime}, 7^{\prime}$-dichlorofluorescein diacetate (DCFH-DA) and cell Counting Kit-8 (CCK-8) were purchased from Keygen Biotech Company (Nanjing, China). FerroOrange was purchased from Dojindo Molecular Technologies Company. Roswell Park Memorial Institute-1640 (RPMI-1640) medium, Dulbecco's modified Eagle's (DMEM) medium, penicillin/streptomycin solution, fetal bovine serum (FBS), and trypsin-ethylene diamine tetraacetic acid (TrypsinEDTA, 0.05\%) were purchased from Gibco BRL (Grand Island, NY, United States). The water used in the experiment was deionized water.

\section{Characterization}

The morphology of nanoparticles was tested by a Tecnai G2 20 TWIN transmission electron microscope (TEM) at an accelerating voltage of $200 \mathrm{kV}$ and a Zeiss Ultra 55 field emission scanning electron microscope (FESEM) equipped with a fieldemission gun operated at $5 \mathrm{kV}$ (Kong et al., 2014). Magnetic characterization curves were measured by a Quantum vibrating sample magnetometer (VSM) at $300 \mathrm{~K}$. Dynamic light scattering (DLS) data, including the size, zeta potential and light scattering intensity of the nanoparticles were measured at $25^{\circ} \mathrm{C}$ on a Zetasizer Nano ZS90 analyzer (Malvern Instrument Ltd). Fourier transform infrared (FT-IR) spectra were obtained via a FT-IR spectrometer (Thermofisher Nicolet 6700). Ultraviolet spectrophotometer (UV-Vis) spectra were recorded at $25^{\circ} \mathrm{C}$ on a Perkin-Elmer Lambda 750 spectrophotometer. The concentration of metal ions was obtained on a P-4010 inductively coupled plasma-atomic emission spectrometry (ICPAES). Confocal laser scanning microscopy (CLSM) images were acquired using a Nikon C2 + laser scanning confocal microscope. Flow cytometry analysis was operated on a flow cytometer (Beckman Coulter Gallios) at $37^{\circ} \mathrm{C}$.

\section{Synthesis of Magnetic Nanoparticles}

Magnetic nanoparticles (MNP) were prepared via a modified solvothermal reaction (Wang $\mathrm{K}$. et al., 2019). $\mathrm{FeCl}_{3} \cdot 6 \mathrm{H}_{2} \mathrm{O}$ $(1.8 \mathrm{~g}), \mathrm{Na}_{3} \mathrm{Cit} \cdot 2 \mathrm{H}_{2} \mathrm{O}(1.2 \mathrm{~g})$ and $\mathrm{NaOAc}(4.8 \mathrm{~g})$ were dissolved in $88 \mathrm{~mL}$ ethylene glycol with sonicated in an ultrasonic bath for $10 \mathrm{~min}$, then the mixture was stirred vigorously for $30 \mathrm{~min}$. The resulting solution was then transferred into a autoclave, which was sealed and heated for $12 \mathrm{~h}$ at $200^{\circ} \mathrm{C}$. After cooling down to room temperature, separated by a magnet, the product was washed alternately with ethanol and deionized water for three times, then redispersed in water for subsequent use.

\section{Preparation and Release Study of Drug-Loaded MNP in vitro}

Three drugs were loaded into MNP, including ART, DHA, AS, respectively. $6 \mathrm{mg}$ of MNP were added into $2 \mathrm{~mL}$ of deionized water and then sonicated for $5 \mathrm{~min}$ to form a homogeneous dispersion. Then $1.5 \mathrm{mg}$ of ART dissolved in $1 \mathrm{~mL}$ of ethanol was added to the dispersion and the dispersion was shaken up for $24 \mathrm{~h}$ at room temperature. Subsequently, liquid of the dispersion was removed by rotary evaporation at $40^{\circ} \mathrm{C}$. The product was washed with water for three times via a magnet and then collected for further use. After treating with $\mathrm{NaOH}-$ containing ethanol solution at $50^{\circ} \mathrm{C}$ for $30 \mathrm{~min}$, the unloaded ART in the collected supernatant was converted to a UV active compound and detected by a UV-visible spectrometry at an excitation wavelength of $292 \mathrm{~nm}$. According to the following formulation, the drug loading contents (LC) were calculated: LC $(\%)=$ (the drug loaded in MNP weight $) /($ total nanoparticles weight) $\times 100 \%$.

The methods of loading DHA and AS into MNP were similar to the above method, except the mass ratio of MNP and the drug, and the volume ratio of water and ethanol. When loading DHA into MNP, $10 \mathrm{mg}$ of MNP were added into $2 \mathrm{~mL}$ of deionized water and then $3 \mathrm{mg}$ of DHA dissolved in $2 \mathrm{~mL}$ of ethanol was added to the dispersion. When loading AS into MNP, $10 \mathrm{mg}$ of MNP were added into $4.95 \mathrm{~mL}$ of deionized water and then $3 \mathrm{mg}$ of AS dissolved in $0.05 \mathrm{~mL}$ of ethanol was added to the dispersion. Furthermore, the method of converting drugs to UV active compounds was different between different drugs. In order to be measured at the wavelength of $238 \mathrm{~nm}$, DHA was treated with ethanol solution containing $\mathrm{NaOH}$ at $60^{\circ} \mathrm{C}$ for $30 \mathrm{~min}$ and $\mathrm{AS}$ was treated with $\mathrm{NaOH}$ solution $(0.1 \mathrm{M})$ at $83^{\circ} \mathrm{C}$ for $1 \mathrm{~h}$. The stability of drug-loaded nanoparticles in phosphate buffer saline (PBS, $\mathrm{pH}$ 7.4) and serum-containing culture medium was detected via monitoring the hydrodynamic size and polydispersity index (PDI) by DLS (Xie et al., 2018).

The drug release behaviors were studied via an incubator shaker at $37^{\circ} \mathrm{C}$ (Ma et al., 2012). Sealed in a $1.4 \times 10^{4}$ Dalton dialysis bag, $2 \mathrm{~mL}$ of drug-loaded MNP were immersed into $200 \mathrm{~mL}$ of PBS ( $\mathrm{pH}$ 7.4) and incubated under oscillation. At predetermined time intervals, $2 \mathrm{~mL}$ of release solution was withdrawn and replaced by an equal volume of fresh buffer. Through UV-visible spectrometry, the concentration of drug released from nanoparticles was obtained. Cumulative drug release was calculated as a percentage of the total drug loaded in MNP and plotted over time. All measurements were performed three times.

\section{Cell Culture}

Human embryonic kidney cell line (HEK-293T cells, normal cells), human breast cancer cell line (MCF-7, MDA-MB-231, and MDA-MB-453 cells, tumor cells), and human breast 
drug-resistant cancer cell line (MCF-7/ADR cells, tumor cells) were purchased from Chinese Science Academy. HEK293T, MCF-7, and MDA-MB-231 cells were cultured in DMEM supplemented with $10 \%(\mathrm{v} / \mathrm{v})$ FBS and $1 \%$ antibiotics (penicillin/streptomycin, $100 \mathrm{U} / \mathrm{mL}$ ). MDA-MB-453 and MCF7/ADR cells were cultured in RPMI-1640 containing $10 \%$ (v/v) FBS, $1 \%$ antibiotics (penicillin/streptomycin, $100 \mathrm{U} / \mathrm{mL}$ ), and DOX $(0.5 \mathrm{mg} / \mathrm{mL})$ was added to the cell culture medium of MCF7/ADR cells. Cells were incubated in an atmosphere of $5 \% \mathrm{CO}_{2}$ at $37^{\circ} \mathrm{C}$.

\section{Cytotoxicity Assays}

The cytotoxicity of nanoparticles was tested on cells using a standard CCK-8 assay (Jiang et al., 2017; Yao et al., 2019). Cells were incubated in 96 pore plates at an initial density of $1 \times 10^{4} /$ well for $24 \mathrm{~h}$ at $37^{\circ} \mathrm{C}$ and under $5 \% \mathrm{CO}_{2}$ atmosphere. Then different concentrations of MNP, drugs and drug-loaded MNP (100 $\mu \mathrm{L} /$ well) dispersions were added in each well and coincubated with cells for $24 \mathrm{~h}$, respectively. At last, CCK8/culture medium $(10 \mu \mathrm{L} / 100 \mu \mathrm{L})$ was added into each well for another $1 \mathrm{~h}$ incubation. The absorbance at $450 \mathrm{~nm}$ of each well was measured using a BioTek enzyme-linked immunosorbent assay reader. All measurements were repeated in triplicate.

\section{Acid-Responsive Behaviors}

To investigate the acid degradation performance of MNP, the concentrations of iron ions generated via MNP at PBS $(\mathrm{pH}$ 7.4 and 5.0) were measured by an inductively coupled plasma spectrometer (ICP). MNP $(200 \mu \mathrm{g} / \mathrm{mL})$ were sealed in a $1.4 \times 10^{4}$ Dalton dialysis bag and incubated in $200 \mathrm{~mL}$ of PBS ( $\mathrm{pH} 7.4$ and 5.0) at $37^{\circ} \mathrm{C}$ under oscillation, respectively (Li et al., 2012b). At different time points, $2 \mathrm{~mL}$ of release solution was removed and replaced with an equal volume of fresh solution. The histogram of iron ion concentration at different times was plotted. Each measurement was repeated three times.

\section{Detection of Cellular $\mathrm{Fe}^{2+}$ Ions Generation}

To clarify $\mathrm{Fe}^{2+}$ ions generation via the nanoparticles in cells, CLSM measurement was performed. MCF-7/ADR cells were seeded in confocal dishes at the density of $1 \times 10^{5}$ cells $/ \mathrm{mL}$, cultured for $24 \mathrm{~h}$, and then MNP, DHA, MNP-DHA dispersions (200 $\mu \mathrm{g} / \mathrm{mL})$ were added into dishes, respectively. Meanwhile, a dish without adding samples was prepared as a control group. After incubated for $6 \mathrm{~h}$, the culture medium was removed and cells were washed with PBS three times. Then FerroOrange $\left(1 \mu \mathrm{M}\right.$, an intracellular $\mathrm{Fe}^{2+}$ ions probe, Ex: $543 \mathrm{~nm}, \mathrm{Em}: 580 \mathrm{~nm}$ ) dispersed in serum-free medium was added to the cells, and cells were incubated for $30 \mathrm{~min}$ in a $37^{\circ} \mathrm{C}$ incubator equilibrated with $95 \%$ air and $5 \% \mathrm{CO}_{2}$. Finally, the fluorescence images of cells were captured using a $\mathrm{C} 2+$ confocal microscope.

\section{Detection of ROS Generation in vitro}

In order to measure the generation of ROS, DPBF was selected as the ROS trapper, which can be oxidized by ROS resulting in fluorescence quenching (Ding et al., 2018). Typically, DPBF
$(10 \mu \mathrm{M}), \mathrm{FeSO}_{4} \cdot 7 \mathrm{H}_{2} \mathrm{O}(100 \mu \mathrm{M})$ and DHA $(100 \mu \mathrm{M})$ were dissolved in ethanol quickly, and the above mixture was measured by the UV-vis spectrophotometer for $0,2,5,10,20,30,60,90$, and $120 \mathrm{~min}$ at the wavelength of $410 \mathrm{~nm}$, respectively.

The production of ROS in MCF-7 and MCF-7/ADR cells was detected by CLSM and flow cytometry (Yang et al., 2019). DCFH-DA, as a ROS probe, was used to assess intracellular ROS generation ability. Cells were seeded in confocal dishes at a density of $1 \times 10^{5}$ cells $/ \mathrm{mL}$ and incubated for $24 \mathrm{~h}$ to allow cell attachment. Then cells were incubated with different materials, respectively and the plate without adding samples was as a control group. After incubated for $6 \mathrm{~h}$, the culture medium was removed and cells stained with $1 \mathrm{~mL}$ of DCFH-DA $(10 \mu \mathrm{M})$ dissolved in PBS at $37^{\circ} \mathrm{C}$ for $30 \mathrm{~min}$. Afterward, PBS containing DCFHDA was removed and cells were rinsed three times with fresh PBS. The fluorescence images of cells were captured using a $\mathrm{C} 2+$ confocal microscope.

Besides, using a flow cytometer ROS production was quantitatively measured. Cells were seeded onto a 6-well plate at a density of $1 \times 10^{5}$ cells $/ \mathrm{mL}$ and treated as the similar steps above to be dyed. Then cells were digested and transferred into centrifuge tubes. Cells were separated via centrifugation for $5 \mathrm{~min}$ at $1000 \mathrm{rpm}$ and redispersed in PBS $(0.5 \mathrm{~mL})$. The fluorescence intensity of DCF was tested by the flow cytometry.

\section{RESULTS AND DISCUSSION}

\section{Preparation and Characterization of Drug-Loaded MNP}

The synthesis method of MNP was slightly modified based on the published solvothermal method (Deng et al., 2005). The detailed morphological and structural features of MNP were examined by TEM, demonstrating the rough surface and the uniform morphology with the particle size of $\sim 180 \mathrm{~nm}$ (Figure 1A). Meanwhile, FESEM images also showed the spherical structure of MNP (Figure 1B). In addition, the magnetic hysteresis curves showed no evident remanence and coercivity, suggesting superparamagnetic property of MNP (Figure 1C). The inset photo that MNP were separated via a magnet also revealed MNP had very good magnetism (Li et al., 2012a; Peng et al., 2017).

As shown in Figure 1D and Supplementary Table S1, the hydrodynamic diameter (Dh) of MNP was $200 \mathrm{~nm}$ with a narrow PDI of 0.013. After loading drugs, including ART, DHA and AS, the average sizes of MNP-ART, MNP-DHA, and MNP-AS were 212, 204, and $204 \mathrm{~nm}$, and the PDI were 0.065, 0.026, and 0.092 , respectively, which implied that the load of drugs didn't affect the stability of nanoparticles. Furthermore, the particle size, as shown by DLS, was larger than that shown by TEM and SEM, which was probably due to the interaction between nanoparticles and surrounding water molecules. The particle size of MNP in serum-containing culture medium increased slightly with time (Supplementary Figure S1), but didn't change much, and all were below $250 \mathrm{~nm}$ within 5 days. The increase in particle size was due to the adsorption of proteins in the dispersion on MNP surface (Kim et al., 2003). The PDI values within 5 days were very small, all less than 0.12 , indicating 
A

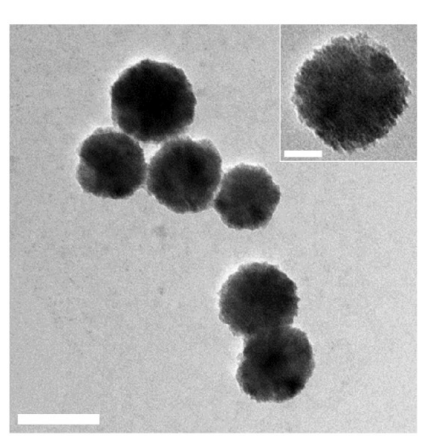

D

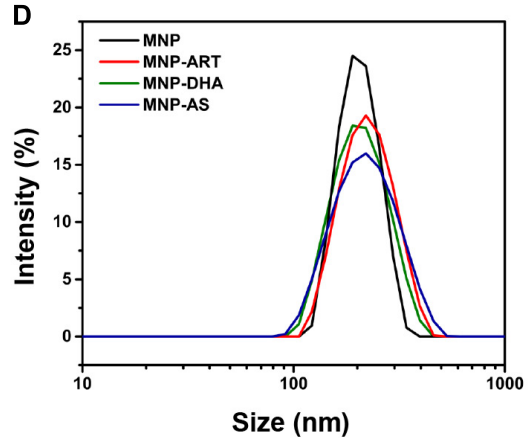

B

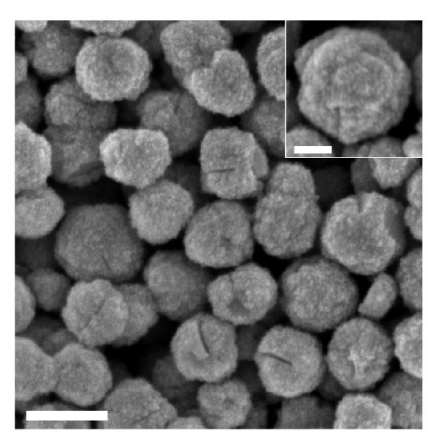

E

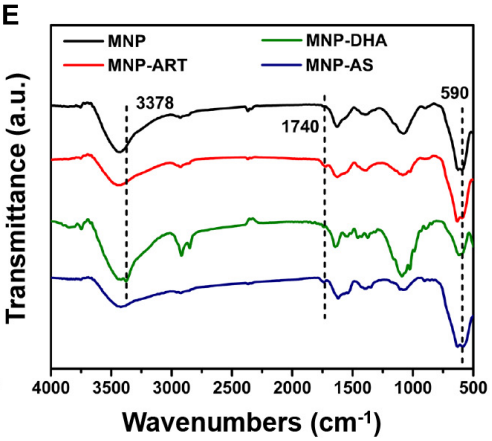

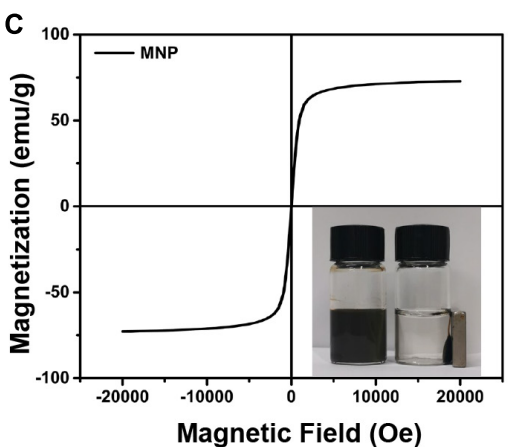

$\mathbf{F}$

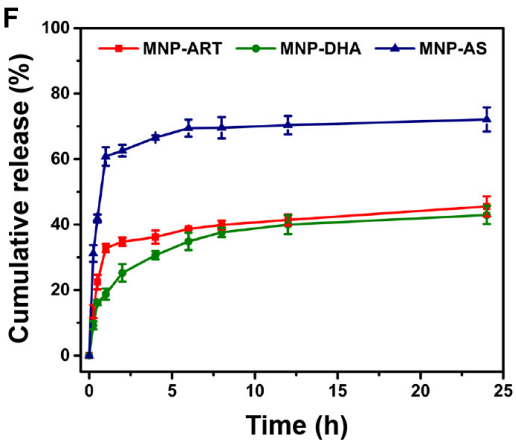

FIGURE 1 | TEM images of (A) MNP. FESEM images of (B) MNP. The scale bars represent 200 nm and the scale bars of insets are 50 nm. (C) Magnetic hysteresis curves of MNP. (D) DLS curves of MNP, MNP-ART, MNP-DHA, and MNP-AS in PBS (pH 7.4). (E) FT-IR spectra of MNP, MNP-ART, MNP-DHA, and MNP-AS. (F) Cumulative drug release from MNP-ART, MNP-DHA, and MNP-AS in PBS (pH 7.4).

that the particle size distribution was even, and proteins were slightly adsorbed. Therefore, the MNP also had good stability in serum-containing culture medium.

The FT-IR spectra demonstrated the successful loading of drugs (Figure 1E and Supplementary Figure S2). The characteristic peak at $590 \mathrm{~cm}^{-1}$ was attributed to $\mathrm{Fe}-\mathrm{O}$ bond (Sanati et al., 2019). After ART loading, the spectrum of the MNPART exhibited new band in the $1740 \mathrm{~cm}^{-1}$ region, which belongs to $\mathrm{C}=\mathrm{O}$ in $\delta$-lactone of ART. In the same way, the absorption peaks at 3378 and $1740 \mathrm{~cm}^{-1}$ belong to $\mathrm{O}-\mathrm{H}$ of $\mathrm{DHA}$ and $\mathrm{C}=\mathrm{O}$ of AS, respectively (Ding et al., 2018; Kumar et al., 2019). The loading ratios of the three drugs were further measured by the UV-vis spectra. According to the standard curves of three drugs (Supplementary Figure S3), the LC could be calculated that ART, DHA, and AS were loaded in MNP with contents of 15.3, 15.3 and $15.7 \%$, respectively. By the way, the LC of three drugs were all very close to $15 \%$, which was deliberately controlled via adjusting the mass ratio of MNP to the drug, and with the similar drug LC, latter experiments could be more comparable. In addition, the TEM images illustrated that the morphology of the nanoparticles barely changed after loading drugs, which indicated that the drug-loaded nanoparticles were still stable (Supplementary Figure S4).

In order to understand the drug release behavior, the drug release profiles of drug-loaded MNP were investigated. As shown in Figure 1F, the cumulative release of ART was about $45.5 \%$ and DHA was about $42.9 \%$ over $24 \mathrm{~h}$, which confirmed that the capacities of MNP to hold ART and DHA in physiological environment were similar. Actually, the solubility of DHA was slightly lower than ART, so during the first $2 \mathrm{~h}$ of the release process, ART exhibited a distinct rapid release behavior, which DHA didn't (Wang et al., 2007; Ansari et al., 2011). In addition, the cumulative release of AS reached $72.1 \%$ over $24 \mathrm{~h}$, indicating that AS was more hydrophilic than ART and DHA, which was consistent with the reported work (Xu R.J. et al., 2019). Similarly, AS also had obvious burst release behavior in the first $2 \mathrm{~h}$. This was actually one of the reasons why we selected MNP-DHA as the optimal system for subsequent experiments.

\section{In vitro Biocompatibility and Cytotoxicity Assays}

The cytotoxicity of nanoparticles to different cells was assessed using CCK-8 assays (Jiang et al., 2017). After incubation with blank MNP for $24 \mathrm{~h}$, there was no obvious toxic effect on HEK$293 \mathrm{~T}$ cells, and cell viability retained above $90 \%$ even with a high concentration up to $200 \mu \mathrm{g} / \mathrm{mL}$, which indicated good biocompatibility of blank MNP (Supplementary Figure S5).

To evaluate the cytotoxicity of ART and its derivatives to cancer cells, MCF-7 cells were incubated with blank MNP, the drugs and the drug-loaded MNP for $24 \mathrm{~h}$, respectively. As shown in Figures 2A-C, all CCK-8 assays displayed dose dependent cell viability. Cells treated by blank MNP still remained high viability at the concentration of $200 \mu \mathrm{g} / \mathrm{mL}$. From the results of free-drug groups, the inhibitory effects of ART and AS to cancer cells were also not good enough at various concentrations. 

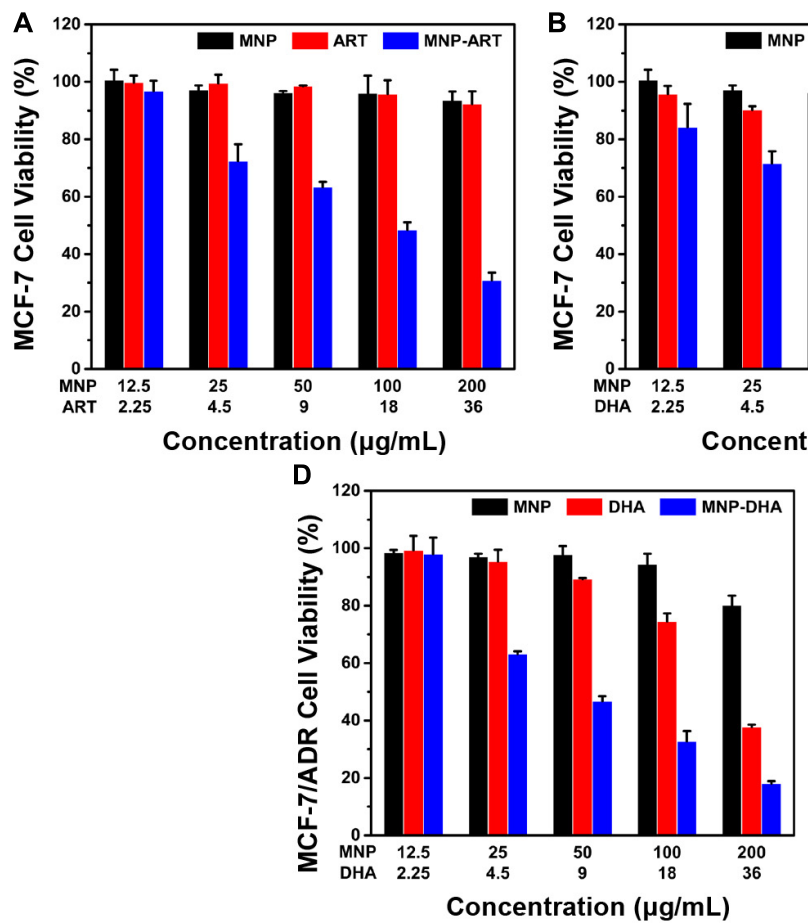
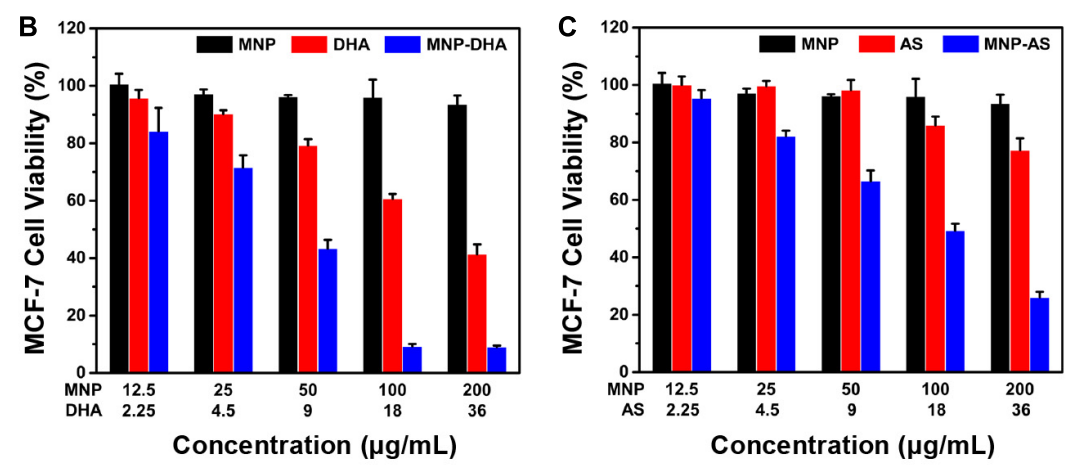

E

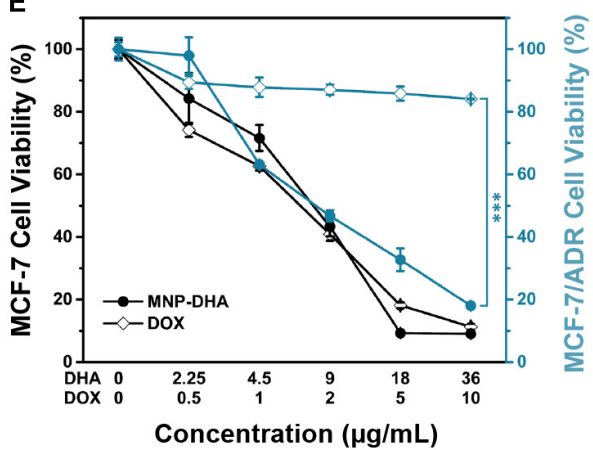

FIGURE 2 | MCF-7 cell viability after incubated with MNP, free drugs, and MNP-drug dispersions at different concentrations for 24 h, respectively: (A) ART, (B) DHA, (C) AS. (D) MCF-7/ADR cell viability after incubated with MNP, free DHA, and MNP-DHA suspensions at different concentrations for 24 h. (E) A comparison of the inhibitory effect of MCF-7 and MCF-7/ADR cells treated with free DOX and MNP-DHA.

However, simultaneous delivery of drugs and MNP into cancer cells all exhibited sharply enhanced cytotoxicity. For instance, in the blank MNP group, the cell viability decreased by only $4 \%$ at a concentration of $100 \mu \mathrm{g} / \mathrm{mL}$, and at free ART, DHA, and AS concentrations of $18 \mu \mathrm{g} / \mathrm{mL}$, the cell viability decreased by 4,39 , and $14 \%$, respectively, while in the corresponding concentrations of MNP-ART, MNP-DHA, and MNP-AS groups, the cell viability was reduced by approximately 49, 90, and 50\%, respectively, which is far greater than the sum of cell viability reduced by the two agents alone. What's more, the inhibitory effect of MNP-ART on MCF-7 cells at $48 \mathrm{~h}$ was more evident than at $24 \mathrm{~h}$, but the difference was not significant (Supplementary Figure S6). This finding showed that ART and its derivatives had a particularly significant enhancement to MNP of inhibitory effects on cell viability, even exceeding the killing effect of the agent itself.

The MNP-DHA, which had the best effect on inhibiting cancer cell viability in three MNP loading ART-based drugs, was selected for subsequent experiments. After calculation, the half inhibitory concentration ( $\mathrm{IC}_{50}$ ) of free DHA was $26.10 \mu \mathrm{g} / \mathrm{mL}$, which was significantly reduced after loading into MNP, changing to $7.76 \mu \mathrm{g} / \mathrm{mL}$. It was shown that MNP-DHA had a better effect on killing cancer cells than free DHA, which meant the enhancement effects of materials and drugs is mutual, and further demonstrated that the combined use of DHA and MNP was an excellent strategy for enhancing killing cells effects.

According to previous reports, ART and its derivatives were sensitive to drug-resistant tumor cells, so we tried to use MNPDHA to carry out cytotoxicity experiments on MCF-7/ADR cell lines (Zhong et al., 2016; Hu et al., 2019). As shown in Figure 2D, only 33\% cell viability was obtained after treatment by MNP-DHA at a concentration of $100 \mu \mathrm{g} / \mathrm{mL}$. The results showed that MNP-DHA also had a great killing effect to MCF7/ADR cells. To compare the therapeutic effects on drug-resistant cancer cells between MNP-DHA and DOX, the cytotoxicity of DOX on the MCF-7 and MCF-7/ADR cell lines was evaluated. After treatment of cells with free DOX for $24 \mathrm{~h}$, MCF-7 cell viability decreased rapidly, while the viability of MCF-7/ADR cells showed little change (Figure 2E). Whereas, whether MCF-7 or MCF-7/ADR cells, their survival rate became very low after treatment with MNP-DHA for $24 \mathrm{~h}$. Consistent with published studies, the results showed that DHA wasn't a P-gp substrate, as a consequence, DHA could bypass P-gp mediated MDR (Crowe et al., 2006; Wang Y. et al., 2019). This finding demonstrated that the proposed MNP-DHA could overcome the MDR of MCF-7/ ADR cells and induce high cytotoxicity.

\section{In vitro Study of $\mathrm{Fe}^{2+}$ Ions Generation}

The participation of a large number of ferrous ions was essential for the high efficiency of CDT, so it was necessary to evaluate the dissolving process of MNP in an acidic environment (PBS, $\mathrm{pH}$ 5.0), which simulated the acidic condition in the tumor microenvironment (Breunig et al., 2008; Hao et al., 2010; Wang et al., 2016; Zhang H. et al., 2016). The acid degradation experiments were carried out in PBS of different acidity $(\mathrm{pH}$ 7.4 and 5.0). Certified by the ICP-AES, the released iron ions increased with continuously degradation of $\mathrm{MNP}$ and as the $\mathrm{pH}$ 

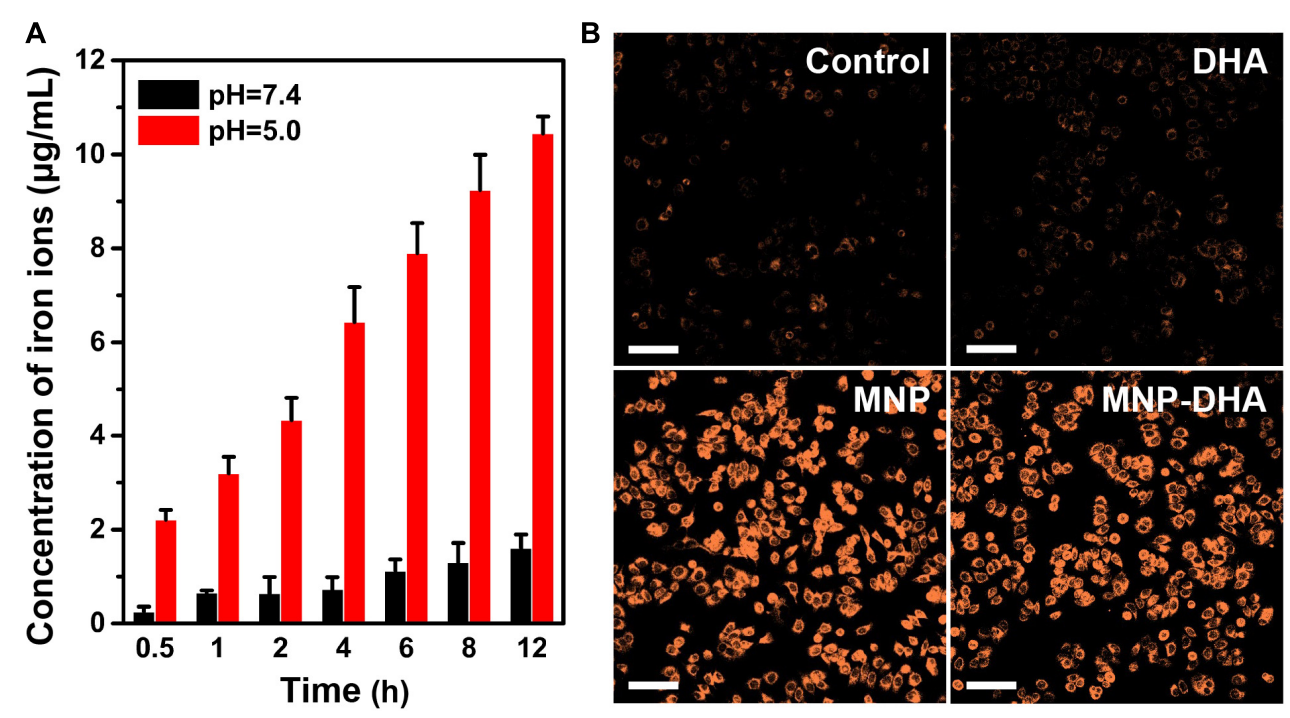

FIGURE 3 | (A) The quantitative analysis of iron ions released from pH-sensitive MNP at different pH (7.4 and 5.0) environment. (B) CLSM images of MCF-7/ADR cells collected to visualize the intracellular $\mathrm{Fe}^{2+}$ ions generation using the $\mathrm{Fe}^{2+}$ ions fluorescent probe Ferrorange. The scale bars are $100 \mu \mathrm{m}$.

value of PBS decreased, MNP exhibited more severe degradation. After $12 \mathrm{~h}$, the Fe concentration in the $\mathrm{pH} 7.4$ buffer solution was only $1.61 \mu \mathrm{g} / \mathrm{mL}$, while the concentration of iron ions in the $\mathrm{pH} 5.0$ buffer solution reached up to $10.45 \mu \mathrm{g} / \mathrm{mL}$ (Figure 3A), implying that MNP could be degraded into abundant iron ions in the microenvironment of tumors. Therefore, in theory, the drugs (DHA) would be released faster and more under acidic conditions than neutral condition ( $\mathrm{pH} 7.4$ ).

The generation of $\mathrm{Fe}^{2+}$ ions was corroborated using a $\mathrm{Fe}^{2+}$ ions probe known as Ferrorange, which could react with $\mathrm{Fe}^{2+}$ ions to produce a bright fluorescent substance. Compared with the control and free DHA groups, the cells treated with MNP and MNP-DHA emitted a much stronger orange fluorescence (Figure 3B), indicating an enormous amount of $\mathrm{Fe}^{2+}$ ions generated via MNP.

\section{In vitro CDT Mechanism of MNP-DHA}

It was well-known that endoperoxide linkages could be cleaved with ferrous ions to generate ROS via a Fenton-like route, which further caused apoptosis or ferroptosis of cells (Efferth et al., 2004; Ooko et al., 2015). To understand the enhanced mechanism of DHA to CDT, an assessment of the ROS generation ability produced by the reaction of DHA with $\mathrm{Fe}^{2+}$ ions was investigated first. A classical ROS trapper, DPBF, was used to measure ROS generation. As the generation of ROS increased, the absorbance of DPBF decreased (Ding et al., 2018). As shown in Figure 4A, at the beginning of the reaction, DPBF solution had a strong absorption at $412 \mathrm{~nm}$. With the reaction time increasing, the absorbance of DPBF gradually decreased, indicating that ROS was produced gradually through the interaction of DHA and $\mathrm{Fe}^{2+}$ ions over time.

Afterward, we compared the ROS yielding ability of different groups by means of flow cytometry and CLSM, including control, blank MNP, free DHA, and MNP-DHA group. A fluorescent probe DCFH-DA was chosen to test intracellular ROS generation, which enable to produce fluorescent $2^{\prime}, 7^{\prime}$-dichlorofluorescein (DCF) under the combined actions of cellular esterase and ROS (Yuan et al., 2014). The quantitative fluorescence analysis was measured by flow cytometry (Figures 4B,C). Incubated with or without MNP, the MCF-7, and MCF-7/ADR cells showed no significant difference in the fluorescence intensity of DCF, due to the fact that the concentration of $\mathrm{H}_{2} \mathrm{O}_{2}$ in cells was not enough to produce a large amount of ROS with ferrous ions. After incubation with free DHA, the fluorescence intensity of the cells became a little higher, on account of the reaction of naturally existed $\mathrm{Fe}^{2+}$ ions with DHA. After treatment with MNP-DHA, a significant enhancement of DCF fluorescence in both MCF-7 and MCF-7/ADR cells was clearly observed, owing to the ROS generation from $\mathrm{Fe}^{2+}$ ions and DHA brought by DHA-loaded nanoparticles. The experiments suggested that more intracellular ROS were produced after treated by MNP-DHA.

The results of fluorescence imaging agreed well with flow cytometry. As shown in Figure 4D, whether the cell line used in the experiments was MCF-7 or MCF-7/ADR, the fluorescence observed in control and MNP group was faintest. The fluorescence slightly increased in free DHA group, indicating that moderately amount of ROS was generated. In the MNP-DHA group, the fluorescence was greatly enhanced, which was the strongest of the four groups. Therefore, the results verified that the effect of DHA from MNP-DHA on enhancing the production efficiency of intracellular ROS was very significant.

\section{Cytotoxicity Assays of Other Breast Cancer Cells}

In consideration of the high cytotoxicity of MNP-DHA, we tried to use this combination to conduct toxicity experiments on other canonical lethal breast cancer cell lines that were triple negative (MDA-MB-231) and human epidermal growth factor receptor 


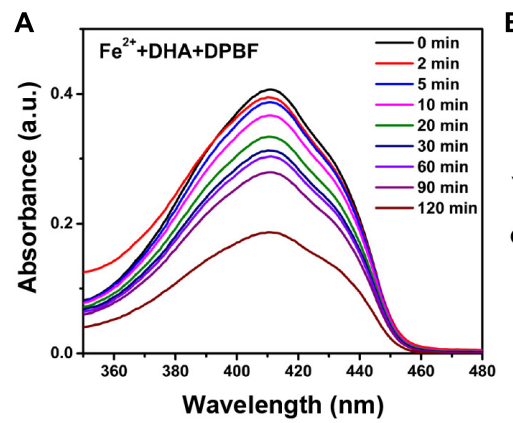

D
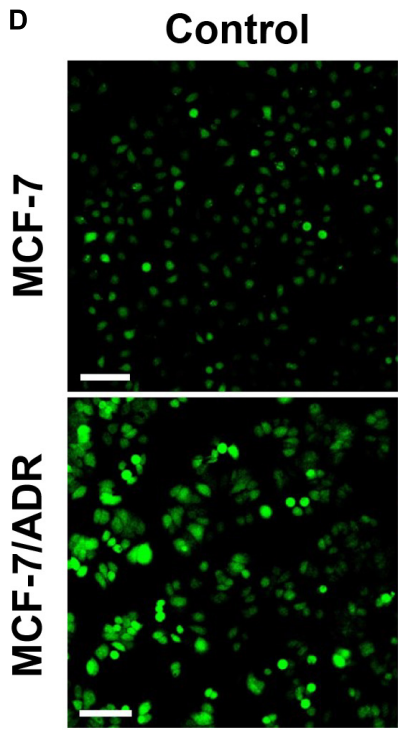

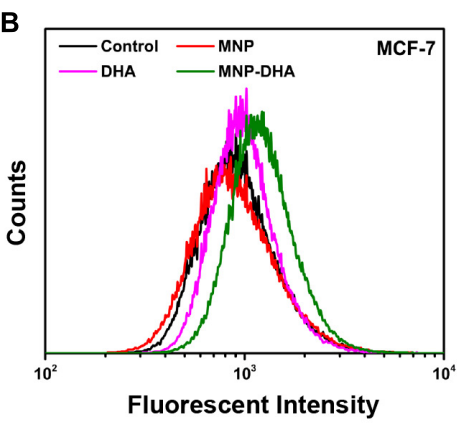

MNP

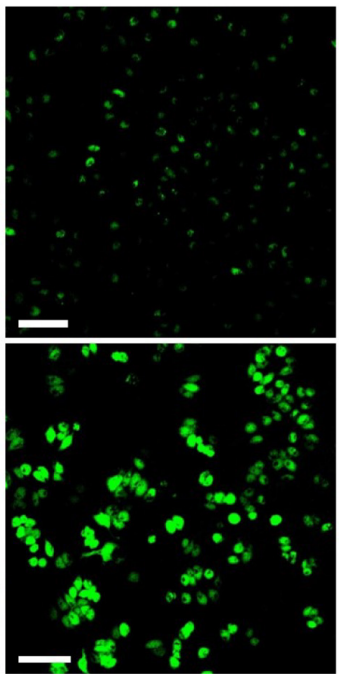

DHA

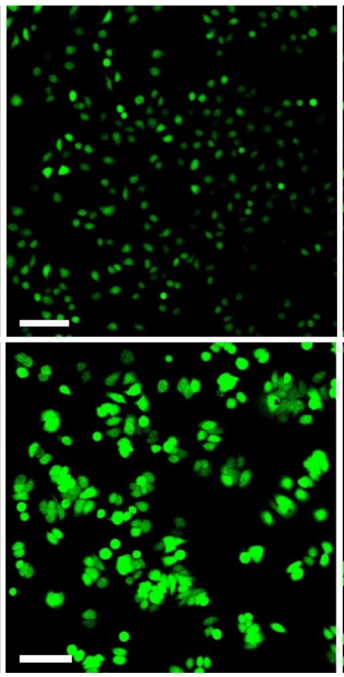

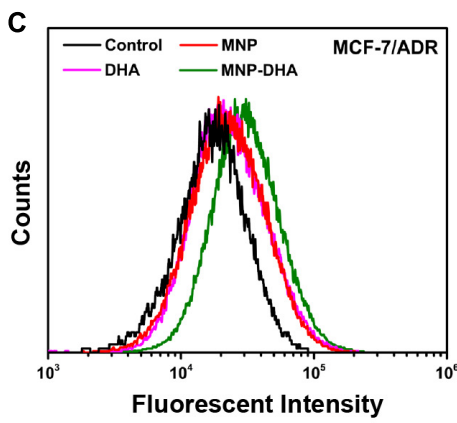

MNP-DHA

FIGURE 4 | (A) The absorption spectra of DPBF at the presence of DHA and Fe'2+ ions at different time. Flow cytometry analyses of ROS generation in (B) MCF-7 and (C) MCF-7/ADR cells detected by DCFH-DA. (D) CLSM images of MCF-7/ADR cells treated under different conditions to evaluate ROS production based on DCF fluorescence intensity using the fluorescent probe DCFH-DA. The scale bars are $100 \mu \mathrm{m}$.
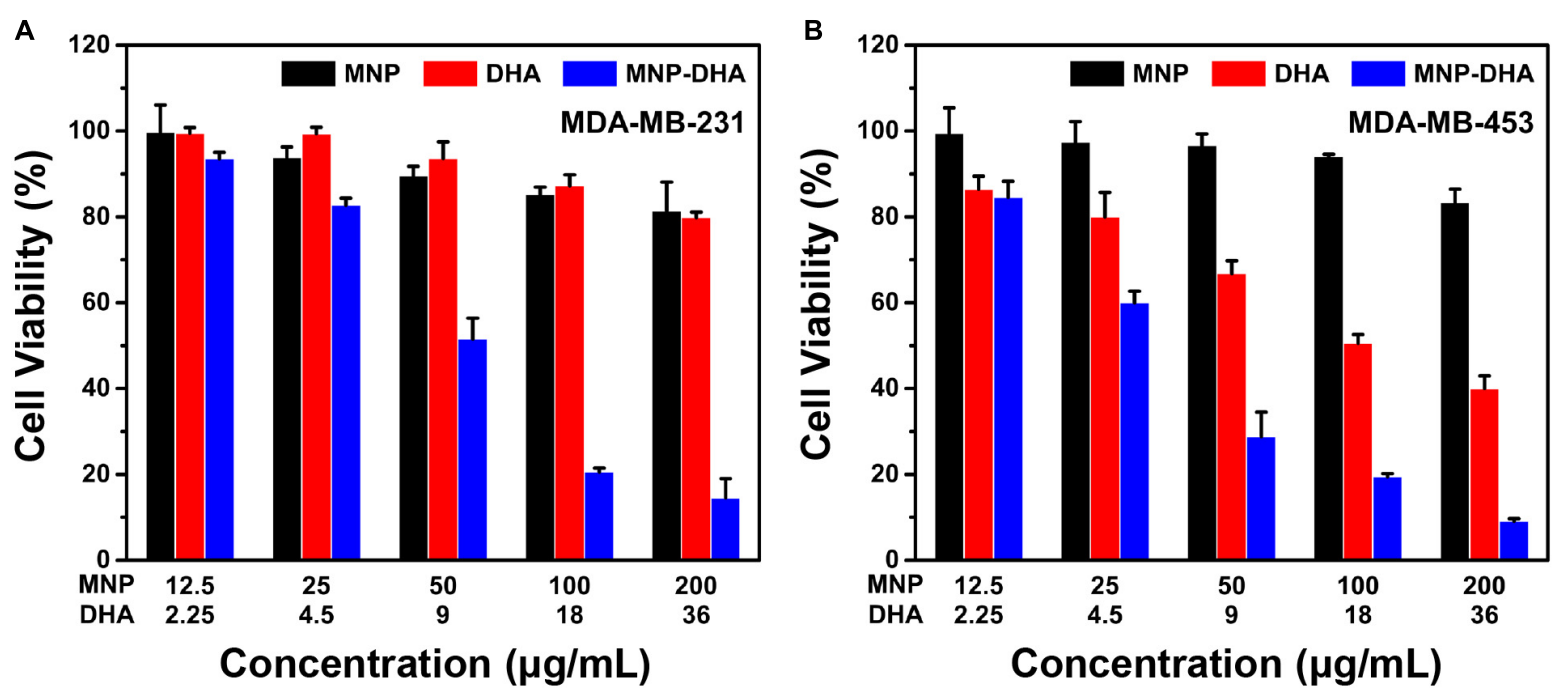

FIGURE 5 | Cell viability of (A) MDA-MB-231, and (B) MDA-MB-453 after 24 h incubation with MNP, free DHA, and MNP-DHA suspensions at different concentrations. 
(HER2) overexpressing (MDA-MB-453) (Neve et al., 2006; Lee et al., 2012). Triple-negative breast cancer, defined by the lack of estrogen receptor, progesterone receptor and HER2, frequently developed resistance to chemotherapy over long-term treatment (Kim et al., 2018; Raninga et al., 2020). HER2 was overexpressed in $25-30 \%$ of breast cancers which was a considerable proportion, and patients with breast cancers that overexpress HER2 had much lower overall survival and disease-free survival due to high metastasis (Baselga et al., 1998; Slamon et al., 2001; Büyükköroğlu et al., 2016). As a consequence, it was of great significance to develop novel therapies for these tumors. As shown in Figure 5, after mixing with $100 \mu \mathrm{g} / \mathrm{mL}$ of MNP-DHA for $24 \mathrm{~h}$, the viability of MDA-MB-231 cells decreased to $21 \%$ and the viability of MDA-MB-453 cells reduced to $19 \%$. This finding made it possible to treat other types of refractory breast cancers via MNP-DHA, nonetheless the specific mechanism needed further research.

\section{CONCLUSION}

In summary, we successfully improved the therapeutic effect of CDT via loading the drugs containing peroxide groups into MNP. Among three MNP loading ART-based drugs, MNP-DHA had the strongest inhibitory effect on breast cancer cells. MNPDHA were capable of specifically performing the Fenton-like reaction in the tumor microenvironment, thereby producing a large amount of ROS to kill tumor cells. In addition, MNPDHA could overcome the P-gp mediated tumor MDR and could be used to treat other aggressive breast tumors. Altogether, the proposed nanoparticles may provide an effective solution for improving the efficacy of CDT treatment and have a good prospect in the treatment of aggressive breast cancers.

\section{REFERENCES}

An, L., Wang, J.-W., Liu, J.-D., Zhao, Z.-M., and Song, Y.-J. (2019). Design, preparation, and characterization of novel calix[4] arene bioactive carrier for antitumor drug delivery. Front. Chem. 7:732. doi: 10.3389/fchem.2019. 00732

Ansari, M. T., Batty, K. T., Iqbal, I., and Sunderland, V. B. (2011). Improving the solubility and bioavailability of dihydroartemisinin by solid dispersions and inclusion complexes. Arch. Pharm. Res. 34, 757-765. doi: 10.1007/s12272-0110509-1

Baselga, J., Norton, L., Albanell, J., Kim, Y. M., and Mendelsohn, J. (1998). Recombinant humanized anti-HER2 antibody (Herceptin (TM)) enhances the antitumor activity of paclitaxel and doxorubicin against HER2/neu overexpressing human breast cancer xenografts. Cancer Res. 58, 2825-2831.

Bokare, A. D., and Choi, W. (2014). Review of iron-free fenton-like systems for activating $\mathrm{H} 2 \mathrm{O} 2$ in advanced oxidation processes. J. Hazard Mater. 275, 121-135. doi: 10.1016/j.jhazmat.2014.04.054

Breunig, M., Bauer, S., and Goepferich, A. (2008). Polymers and nanoparticles: intelligent tools for intracellular targeting? Eur. J. Pharm. Biopharm. 68, 112128. doi: 10.1016/j.ejpb.2007.06.010

Büyükköroğlu, G., Şenel, B., Gezgin, S., and Dinh, T. (2016). The simultaneous delivery of paclitaxel and Herceptin ${ }^{(C)}$ using solid lipid nanoparticles: In vitro evaluation. J. Drug Deliv. Sci. Technol. 35, 98-105. doi: 10.1016/j.jddst.2016. 06.010

Chen, Q., Liang, C., Sun, X., Chen, J., Yang, Z., Zhao, H., et al. (2017). H2O2responsive liposomal nanoprobe for photoacoustic inflammation imaging and

\section{DATA AVAILABILITY STATEMENT}

All datasets generated for this study are included in the article/Supplementary Material.

\section{AUTHOR CONTRIBUTIONS}

SG and WY designed the research. SG, KW, and YZ conducted the experiments. SG, XY, and QJ analyzed the data. SG, WY, JT, and HP wrote the manuscript. WY, JT, and HP supervised the work. All authors have approved the final version of the manuscript.

\section{FUNDING}

This work was supported by the National Natural Science Foundation of China (Grant Nos. 51933002 and 51873041) and the National Key R\&D Program of China (Grant No. 2016YFC1100300).

\section{ACKNOWLEDGMENTS}

We thank Yongbin Cao, Ruihong Xie, Xuechun Zhang, and Jingbo Lin at Fudan for their helpful discussions.

\section{SUPPLEMENTARY MATERIAL}

The Supplementary Material for this article can be found online at: https://www.frontiersin.org/articles/10.3389/fphar. 2020.00226/full\#supplementary-material

tumor theranostics via in vivo chromogenic assay. Proc. Natl. Acad. Sci. U.S.A. 114, 5343-5348. doi: 10.1073/pnas.1701976114

Chen, Y., Deng, J., Liu, F., Dai, P., An, Y., Wang, Z., et al. (2019). Energy-free, singlet oxygen-based chemodynamic therapy for selective tumor treatment without dark toxicity. Adv. Healthc. Mater. 8:e1900366. doi: 10.1002/adhm. 201900366

Cho, M. H., Choi, E. S., Kim, S., Goh, S. H., and Choi, Y. (2017). Redox-responsive manganese dioxide nanoparticles for enhanced $\mathrm{mr}$ imaging and radiotherapy of lung cancer. Front. Chem. 5:109. doi: 10.3389/fchem.2017.00109

Crowe, A., Ilett, K. F., Karunajeewa, H. A., Batty, K. T., and Davis, T. M. (2006). Role of $\mathrm{P}$ glycoprotein in absorption of novel antimalarial drugs. Antimicrob. Agents Chemother. 50, 3504-3506. doi: 10.1128/AAC.00708-06

Deng, H., Li, X., Peng, Q., Wang, X., Chen, J., and Li, Y. (2005). Monodisperse magnetic single-crystal ferrite microspheres. Angew. Chem. Int. Ed. Engl. 44, 2782-2785. doi: 10.1002/anie.200462551

Ding, Y., Wan, J., Zhang, Z., Wang, F., Guo, J., and Wang, C. (2018). Localized $\mathrm{Fe}(\mathrm{II})$-induced cytotoxic reactive oxygen species generating nanosystem for enhanced anticancer therapy. ACS Appl. Mater. Interfaces 10, 4439-4449. doi: 10.1021/acsami.7b16999

Efferth, T., Benakis, A., Romero, M. R., Tomicic, M., Rauh, R., Steinbach, D., et al. (2004). Enhancement of cytotoxicity of artemisinins toward cancer cells by ferrous iron. Free Radic. Biol. Med. 37, 998-1009. doi: 10.1016/j.freeradbiomed. 2004.06.023

Ember, E., Rothbart, S., Puchta, R., and van Eldik, R. (2009). Metal ion-catalyzed oxidative degradation of orange II by $\mathrm{H} 2 \mathrm{O} 2$. High catalytic activity of simple manganese salts. New J. Chem. 33, 34-49. doi: 10.1039/b813725k 
Golenser, J., Waknine, J. H., Krugliak, M., Hunt, N. H., and Grau, G. E. (2006). Current perspectives on the mechanism of action of artemisinins. Int. J. Parasitol. 36, 1427-1441. doi: 10.1016/j.ijpara.2006.07.011

Hao, R., Xing, R., Xu, Z., Hou, Y., Gao, S., and Sun, S. (2010). Synthesis, functionalization, and biomedical applications of multifunctional magnetic nanoparticles. Adv. Mater. 22, 2729-2742. doi: 10.1002/adma.201000260

Hu, Y., Li, N., Zhang, J., Wang, Y., Chen, L., and Sun, J. (2019). Artemisinin-indole and artemisinin-imidazole hybrids: synthesis, cytotoxic evaluation and reversal effects on multidrug resistance in MCF-7/ADR cells. Bioorg. Med. Chem. Lett. 29, 1138-1142. doi: 10.1016/j.bmcl.2019.02.021

Huo, M., Wang, L., Chen, Y., and Shi, J. (2017). Tumor-selective catalytic nanomedicine by nanocatalyst delivery. Nat. Commun. 8:357. doi: 10.1038/ s41467-017-00424-8

Jiang, Q., Luo, Z., Men, Y., Yang, P., Peng, H., Guo, R., et al. (2017). Red blood cell membrane-camouflaged melanin nanoparticles for enhanced photothermal therapy. Biomaterials 143, 29-45. doi: 10.1016/j.biomaterials.2017.07.027

Kim, C., Gao, R., Sei, E., Brandt, R., Hartman, J., Hatschek, T., et al. (2018). Chemoresistance evolution in triple-negative breast cancer delineated by singlecell sequencing. Cell 173, 879-893.e13. doi: 10.1016/j.cell.2018.03.041

Kim, D. K., Mikhaylova, M., Zhang, Y., and Muhammed, M. (2003). Protective coating of superparamagnetic iron oxide nanoparticles. Chem. Mater. 15, 16171627. doi: $10.1021 / \mathrm{cm} 021349 j$

Kong, B., Tang, J., Wu, Z. X., Wei, J., Wu, H., Wang, Y. C., et al. (2014). Ultralight mesoporous magnetic frameworks by interfacial assembly of prussian blue nanocubes. Angew. Chem.-Int. Ed. 53, 2888-2892. doi: 10.1002/anie.201308625

Krishna, S., Uhlemann, A. C., and Haynes, R. K. (2004). Artemisinins: mechanisms of action and potential for resistance. Drug Resist. Updat. 7, 233-244. doi: 10.1016/j.drup.2004.07.001

Kruh, G. D., and Belinsky, M. G. (2003). The MRP family of drug efflux pumps. Oncogene 22, 7537-7552. doi: 10.1038/sj.onc.1206953

Kumar, R., Singh, M., Meena, J., Singhvi, P., Thiyagarajan, D., Saneja, A., et al. (2019). Hyaluronic acid - Dihydroartemisinin conjugate: Synthesis, characterization and in vitro evaluation in lung cancer cells. Int. J. Biol. Macromol. 133, 495-502. doi: 10.1016/j.ijbiomac.2019.04.124

Lee, M. J., Ye, A. S., Gardino, A. K., Heijink, A. M., Sorger, P. K., MacBeath, G., et al. (2012). Sequential application of anticancer drugs enhances cell death by rewiring apoptotic signaling networks. Cell 149, 780-794. doi: 10.1016/j.cell. 2012.03.031

Li, D., Tang, J., Guo, J., Wang, S. L., Chaudhary, D., and Wang, C. C. (2012a). Hollow-core magnetic colloidal nanocrystal clusters with ligand-exchanged surface modification as delivery vehicles for targeted and stimuli-responsive drug release. Chem. A Eur. J. 18, 16517-16524. doi: 10.1002/chem.201202249

Li, D., Tang, J., Wei, C., Guo, J., Wang, S. L., Chaudhary, D., et al. (2012b). Doxorubicin-conjugated mesoporous magnetic colloidal nanocrystal clusters stabilized by polysaccharide as a smart anticancer drug vehicle. Small 8, 26902697. doi: $10.1002 / \mathrm{smll} .201200272$

Li, R., Jin, X., Megharaj, M., Naidu, R., and Chen, Z. (2015). Heterogeneous fenton oxidation of 2,4-dichlorophenol using iron-based nanoparticles and persulfate system. Chem. Eng. J. 264, 587-594. doi: 10.1016/j.cej.2014.11.128

Lin, L. S., Song, J., Song, L., Ke, K., Liu, Y., Zhou, Z., et al. (2018). Simultaneous fenton-like ion delivery and glutathione depletion by $\mathrm{MNO}_{2}$-based nanoagent to enhance chemodynamic therapy. Angew. Chem. Int. Ed. Engl. 57, 4902-4906. doi: 10.1002/anie.201712027

Ma, B., Wang, S., Liu, F., Zhang, S., Duan, J., Li, Z., et al. (2019). Selfassembled copper-amino acid nanoparticles for in situ glutathione "AND" $\mathrm{H} 2 \mathrm{O} 2$ sequentially triggered chemodynamic therapy. J. Am. Chem. Soc. 141, 849-857. doi: 10.1021/jacs.8b08714

Ma, W. F., Wu, K. Y., Tang, J., Li, D., Wei, C., Guo, J., et al. (2012). Magnetic drug carrier with a smart $\mathrm{pH}$-responsive polymer network shell for controlled delivery of doxorubicin. J. Mater. Chem. 22, 15206-15214. doi: 10.1039/ c2jm31721d

Men, Y., Peng, S., Yang, P., Jiang, Q., Zhang, Y., Shen, B., et al. (2018). Biodegradable zwitterionic nanogels with long circulation for antitumor drug delivery. ACS Appl. Mater. Interfaces 10, 23509-23521. doi: 10.1021/acsami. $8 \mathrm{~b} 03943$

Neve, R. M., Chin, K., Fridlyand, J., Yeh, J., Baehner, F. L., Fevr, T., et al. (2006). A collection of breast cancer cell lines for the study of functionally distinct cancer subtypes. Cancer Cell 10, 515-527. doi: 10.1016/j.ccr.2006.10.008
Olliaro, P. L., Haynes, R. K., Meunier, B., and Yuthavong, Y. (2001). Possible modes of action of the artemisinin-type compounds. Trends Parasitol. 17, 122-126. doi: 10.1016/S1471-4922(00)01838-9

Ooko, E., Saeed, M. E., Kadioglu, O., Sarvi, S., Colak, M., Elmasaoudi, K., et al. (2015). Artemisinin derivatives induce iron-dependent cell death (ferroptosis) in tumor cells. Phytomedicine 22, 1045-1054. doi: 10.1016/j.phymed.2015. 08.002

Osaki, T., Tajima, M., Okamoto, Y., Takagi, S., Tsuka, T., Imagawa, T., et al. (2011). Sonodynamic antitumor effect of benzoporphyrin derivative monoacid ring A on KLN205 Cells. J. Cancer Ther. 02, 99-104. doi: 10.4236/jct.2011.22011

Peng, H. B., Tang, J., Zheng, R., Guo, G. N., Dong, A. G., Wang, Y. J., et al. (2017). Nuclear-targeted multifunctional magnetic nanoparticles for photothermal therapy. Adv. Healthc. Mater. 6, doi: 10.1002/adhm.201601289

Poyton, M. F., Sendecki, A. M., Cong, X., and Cremer, P. S. (2016). Cu(2+) binds to phosphatidylethanolamine and increases oxidation in lipid membranes. J. Am. Chem. Soc. 138, 1584-1590. doi: 10.1021/jacs.5b11561

Prasad, P., Cheng, J., Shuhendler, A., Rauth, A. M., and Wu, X. Y. (2012). A novel nanoparticle formulation overcomes multiple types of membrane efflux pumps in human breast cancer cells. Drug Deliv. Transl Res. 2, 95-105. doi: 10.1007/s13346-011-0051-1

Raninga, P. V., Lee, A. C., Sinha, D., Shih, Y. Y., Mittal, D., Makhale, A., et al. (2020). Therapeutic cooperation between auranofin, a thioredoxin reductase inhibitor and anti-PD-L1 antibody for treatment of triple-negative breast cancer. Int. J. Cancer 146, 123-136. doi: 10.1002/ijc.32410

Reed, J. C., and Pellecchia, M. (2012). Ironing out cell death mechanisms. Cell 149, 963-965. doi: 10.1016/j.cell.2012.05.009

Sanati, A. M., Kamari, S., and Ghorbani, F. (2019). Application of response surface methodology for optimization of cadmium adsorption from aqueous solutions by Fe3O4@SiO2@APTMS core-shell magnetic nanohybrid. Surf. Interfaces 17:100374. doi: 10.1016/j.surfin.2019.100374

Slamon, D. J., Leyland-Jones, B., Shak, S., Fuchs, H., Paton, V., Bajamonde, A., et al. (2001). Use of chemotherapy plus a monoclonal antibody against HER2 for metastatic breast cancer that overexpresses HER2. N. Engl. J. Med. 344, 783-792. doi: 10.1056/Nejm200103153441101

Song, G., Liang, C., Yi, X., Zhao, Q., Cheng, L., Yang, K., et al. (2016). Perfluorocarbon-loaded hollow Bi2Se3 nanoparticles for timely supply of oxygen under near-infrared light to enhance the radiotherapy of cancer. $A d v$. Mater. 28, 2716-2723. doi: 10.1002/adma.201504617

Sun, X., Yan, P., Zou, C., Wong, Y. K., Shu, Y., Lee, Y. M., et al. (2019). Targeting autophagy enhances the anticancer effect of artemisinin and its derivatives. Med. Res. Rev. 39, 2172-2193. doi: 10.1002/med.21580

Szakacs, G., Paterson, J. K., Ludwig, J. A., Booth-Genthe, C., and Gottesman, M. M. (2006). Targeting multidrug resistance in cancer. Nat. Rev. Drug Discov. 5, 219-234. doi: 10.1038/nrd1984

Szatrowski, T. P., and Nathan, C. F. (1991). Production of large amounts of hydrogen-peroxide by human tumor-cells. Cancer Res. 51, 794-798.

Tang, J., Kong, B., Wu, H., Xu, M., Wang, Y. C., Wang, Y. L., et al. (2013). Carbon nanodots featuring efficient FRET for real-time monitoring of drug delivery and two-photon imaging. Adv. Mater. 25, 6569-6574. doi: 10.1002/adma.201303124

Tang, J., Qin, N., Chong, Y., Diao, Y. P., Yiliguma, Wang, Z. X., et al. (2018). Nanowire arrays restore vision in blind mice. Nat. Commun. 9:786. doi: 10.1038/ s41467-018-03212-0

Tang, Z., Liu, Y., He, M., and Bu, W. (2019). Chemodynamic therapy: tumour microenvironment-mediated fenton and fenton-like reactions. Angew. Chem. Int. Ed. Engl. 58, 946-956. doi: 10.1002/anie.201805664

Tu, Y. (2011). The discovery of artemisinin (qinghaosu) and gifts from Chinese medicine. Nat. Med. 17, 1217-1220. doi: 10.1038/nm.2471

Wan, X., Zhong, H., Pan, W., Li, Y., Chen, Y., Li, N., et al. (2019). Programmed release of dihydroartemisinin for synergistic cancer therapy using a $\mathrm{CaCO} 3$ mineralized metal-organic framework. Angew. Chem. Int. Ed. Engl. 58, 1413414139. doi: 10.1002 /anie. 201907388

Wang, D., Zhou, J., Chen, R., Shi, R., Xia, G., Zhou, S., et al. (2016). Magnetically guided delivery of DHA and $\mathrm{Fe}$ ions for enhanced cancer therapy based on $\mathrm{pH}-$ responsive degradation of DHA-loaded Fe3O4@C@MIL-100(Fe) nanoparticles. Biomaterials 107, 88-101. doi: 10.1016/j.biomaterials.2016.08.039

Wang, K., Yang, P., Guo, R., Yao, X., and Yang, W. (2019). Photothermal performance of MFe2O4 nanoparticles. Chin. Chem. Lett. 30, 2013-2016. doi: 10.1016/j.cclet.2019.04.005 
Wang, L. L., Kong, L., Liu, H., Zhang, Y., Zhang, L., Liu, X., et al. (2019). Design and synthesis of novel artemisinin derivatives with potent activities against colorectal cancer in vitro and in vivo. Eur. J. Med. Chem. 182:111665. doi: 10.1016/j.ejmech.2019.111665

Wang, Y., Li, Y., Shang, D., and Efferth, T. (2019). Interactions between artemisinin derivatives and P-glycoprotein. Phytomedicine 60, 152998. doi: 10.1016/j. phymed.2019.152998

Wang, L. H., Song, Y. T., Chen, Y., and Cheng, Y. Y. (2007). Solubility of artemisinin in ethanol plus water from (278.2 to 343.2) K. J. Chem. Eng. Data 52, 757-758. doi: 10.1021/je0603426

Wang, Y., Yin, W., Ke, W., Chen, W., He, C., and Ge, Z. (2018). Multifunctional polymeric micelles with amplified fenton reaction for tumor ablation. Biomacromolecules 19, 1990-1998. doi: 10.1021/acs.biomac.7b01777

Xie, R., Tian, Y., Peng, S., Zhang, L., Men, Y., and Yang, W. (2018). Poly(2methacryloyloxyethyl phosphorylcholine)-based biodegradable nanogels for controlled drug release. Polym. Chem. 9, 4556-4565. doi: 10.1039/c8py00948a

Xu, A., Li, X., Ye, S., Yin, G., and Zeng, Q. (2011). Catalyzed oxidative degradation of methylene blue by in situ generated cobalt (II)-bicarbonate complexes with hydrogen peroxide. Appl. Catal. B Environ. 102, 37-43. doi: 10.1016/j.apcatb. 2010.11.022

Xu, R. J., Han, T., Shen, L., Zhao, J. G., and Lu, X. A. (2019). Solubility determination and modeling for artesunate in binary solvent mixtures of methanol, ethanol, isopropanol, and propylene glycol plus water. J. Chem. Eng. Data 64, 755-762. doi: 10.1021/acs.jced.8b00988

Xu, X., Feng, Y., Chen, X., Wang, Q., Meng, T., and Liu, A. (2019). Antitumor effects of seleno-beta-lactoglobulin on human breast cancer MCF-7 and MDAMB-231 cells in vitro. Toxicol. In Vitro 61:104607. doi: 10.1016/j.tiv.2019.104607

Yan, K. C., Sedgwick, A. C., Zang, Y., Chen, G. R., He, X. P., Li, J., et al. (2019). Sensors, imaging agents, and theranostics to help understand and treat reactive oxygen species related diseases. Small Methods 3:1900013. doi: 10.1002/smtd. 201900013

Yang, P., Men, Y., Tian, Y., Cao, Y., Zhang, L., Yao, X., et al. (2019). Metal-organic framework nanoparticles with near-infrared dye for multimodal imaging and guided phototherapy. ACS Appl. Mater. Interfaces 11, 11209-11219. doi: 10. 1021/acsami.9b01286

Yao, X., Yang, P., Jin, Z., Jiang, Q., Guo, R., Xie, R., et al. (2019). Multifunctional nanoplatform for photoacoustic imaging-guided combined therapy enhanced by CO induced ferroptosis. Biomaterials 197, 268-283. doi: 10.1016/j. biomaterials.2019.01.026
Yao, Y., Guo, Q., Cao, Y., Qiu, Y., Tan, R., Yu, Z., et al. (2018). Artemisinin derivatives inactivate cancer-associated fibroblasts through suppressing TGFbeta signaling in breast cancer. J. Exp. Clin. Cancer Res. 37:282. doi: 10.1186/ s13046-018-0960-7

Yuan, Y., Liu, J., and Liu, B. (2014). Conjugated-polyelectrolyte-based polyprodrug: targeted and image-guided photodynamic and chemotherapy with on-demand drug release upon irradiation with a single light source. Angew. Chem. Int. Ed. Engl. 53, 7163-7168. doi: 10.1002/anie.20140 2189

Yue, J., Liang, L., Shen, Y., Guan, X., Zhang, J., Li, Z., et al. (2018). Investigating dynamic molecular events in melanoma cell nucleus during photodynamic therapy by SERS. Front. Chem. 6:665. doi: 10.3389/fchem.2018.00665

Zhang, C., Bu, W., Ni, D., Zhang, S., Li, Q., Yao, Z., et al. (2016). Synthesis of iron nanometallic glasses and their application in cancer therapy by a localized fenton reaction. Angew. Chem. Int. Ed. Engl. 55, 2101-2106. doi: 10.1002/anie. 201510031

Zhang, H., Chen, Q., Zhang, X., Zhu, X., Chen, J., Zhang, H., et al. (2016). An Intelligent and tumor-responsive $\mathrm{Fe}(2+)$ donor and $\mathrm{Fe}(2+)$-dependent drugs cotransport system. ACS Appl. Mater. Interfaces 8, 33484-33498. doi: 10.1021/ acsami.6b11839

Zheng, D. W., Lei, Q., Zhu, J. Y., Fan, J. X., Li, C. X., Li, C., et al. (2017). Switching apoptosis to ferroptosis: metal-organic network for high-efficiency anticancer therapy. Nano Lett. 17, 284-291. doi: 10.1021/acs.nanolett.6b04060

Zhong, H., Zhao, X., Zuo, Z., Sun, J., Yao, Y., Wang, T., et al. (2016). Combating P-glycoprotein-mediated multidrug resistance with 10-O-phenyl dihydroartemisinin ethers in MCF-7 cells. Eur J Med. Chem. 108, 720-729. doi: 10.1016/j.ejmech.2015.10.040

Conflict of Interest: The authors declare that the research was conducted in the absence of any commercial or financial relationships that could be construed as a potential conflict of interest.

Copyright (c) 2020 Guo, Yao, Jiang, Wang, Zhang, Peng, Tang and Yang. This is an open-access article distributed under the terms of the Creative Commons Attribution License (CC BY). The use, distribution or reproduction in other forums is permitted, provided the original author(s) and the copyright owner(s) are credited and that the original publication in this journal is cited, in accordance with accepted academic practice. No use, distribution or reproduction is permitted which does not comply with these terms. 